\title{
Hypoxia-Inducible Factor-1 as a Therapeutic Target in Endometrial Cancer Management
}

\author{
Laura M. S. Seeber, ${ }^{1}$ Ronald P. Zweemer, ${ }^{1}$ René H. M. Verheijen, ${ }^{1}$ and Paul J. van Diest ${ }^{2}$ \\ ${ }^{1}$ Department of Gynaecological Oncology, University Medical Centre Utrecht, PO Box 85500, 3508 GA Utrecht, The Netherlands \\ ${ }^{2}$ Department of Pathology, University Medical Centre Utrecht, PO Box 85500, 3508 GA Utrecht, The Netherlands
}

Correspondence should be addressed to Paul J. van Diest, p.j.vandiest@umcutrecht.nl

Received 31 October 2009; Accepted 22 December 2009

Academic Editor: Paul J. Hoskins

Copyright ( 92010 Laura M. S. Seeber et al. This is an open access article distributed under the Creative Commons Attribution License, which permits unrestricted use, distribution, and reproduction in any medium, provided the original work is properly cited.

\begin{abstract}
In the Western world, endometrial cancer (EC) is the most common malignant tumor of the female genital tract. Solid tumors like EC outgrow their vasculature resulting in hypoxia. Tumor hypoxia is important because it renders an aggressive phenotype and leads to radio- and chemo-therapy resistance. Hypoxia-inducible factor- $1 \alpha$ (HIF- $1 \alpha$ ) plays an essential role in the adaptive cellular response to hypoxia and is associated with poor clinical outcome in EC. Therefore, HIF-1 could be an attractive therapeutic target. Selective HIF-1 inhibitors have not been identified. A number of nonselective inhibitors which target signaling pathways upstream or downstream HIF-1 are known to decrease HIF- $1 \alpha$ protein levels. In clinical trials for the treatment of advanced and/or recurrent EC are the topoisomerase I inhibitor Topotecan, mTOR-inhibitor Rapamycin, and angiogenesis inhibitor Bevacizumab. Preliminary data shows encouraging results for these agents. Further work is needed to identify selective HIF-1 inhibitors and to translate these into clinical trials.
\end{abstract}

\section{Introduction}

Endometrial cancer is the most common malignant tumour of the female genital tract. The American Cancer Society estimates that 42.160 women will have been diagnosed with, and 7780 women will have died of cancer of endometrial cancer in 2009 in the US [1]. Ninety percent of endometrial cancer cases are sporadic, while the remaining are deemed hereditary. In the endometrium, different adenocarcinoma subtypes can develop. Endometrioid endometrial carcinoma (EEC), or Type 1 cancer, accounts for approximately $75 \%$ of cases. These tumours are usually oestrogen dependent, tend to be of lower grade, and have fewer recurrences and a better survival. They often develop in a background of adenomatous hyperplasia and are characterized by mutations in PTEN and defects in DNA mismatch repair-as manifested by microsatellite instability. Type 2 tumours, of which serous endometrial carcinoma (USPC) is the most common subtype, arise from atrophic endometrium. Type 2 tumours often show p53 and are usually nondiploid. USPCs are often poorly differentiated and have a greater propensity for early spreading. They have worse prognosis than that of EEC.

A developing solid tumour will outgrow its own vasculature beyond the size of several cubic millimetres, resulting in hypoxia (defined as an oxygen tension below the physiological level, $<2 \% \mathrm{pO}_{2}$ ) [2]. Hypoxia has been found to be an important event in carcinogenesis as it renders a more aggressive phenotype with increased invasiveness and proliferation, formation of metastases, and poorer survival in several types of cancer $[3,4]$. Furthermore, it has been shown that hypoxia-induces resistance to radiotherapy and chemotherapy [5-7]. The key survival gene for cells in a hypoxic environment is hypoxia inducible factor-1 (HIF-1) (see Figure 1.).

The unsatisfactory results obtained with conventional pharmacological treatment encourage further biological and clinical investigations addressed to a better understanding of specific cell targets and signalling transduction pathways involved in endometrial carcinogenesis and to the identification of novel molecular therapeutic targets. As hypoxia, and thus HIF-1, leads to resistance to radiotherapy and 


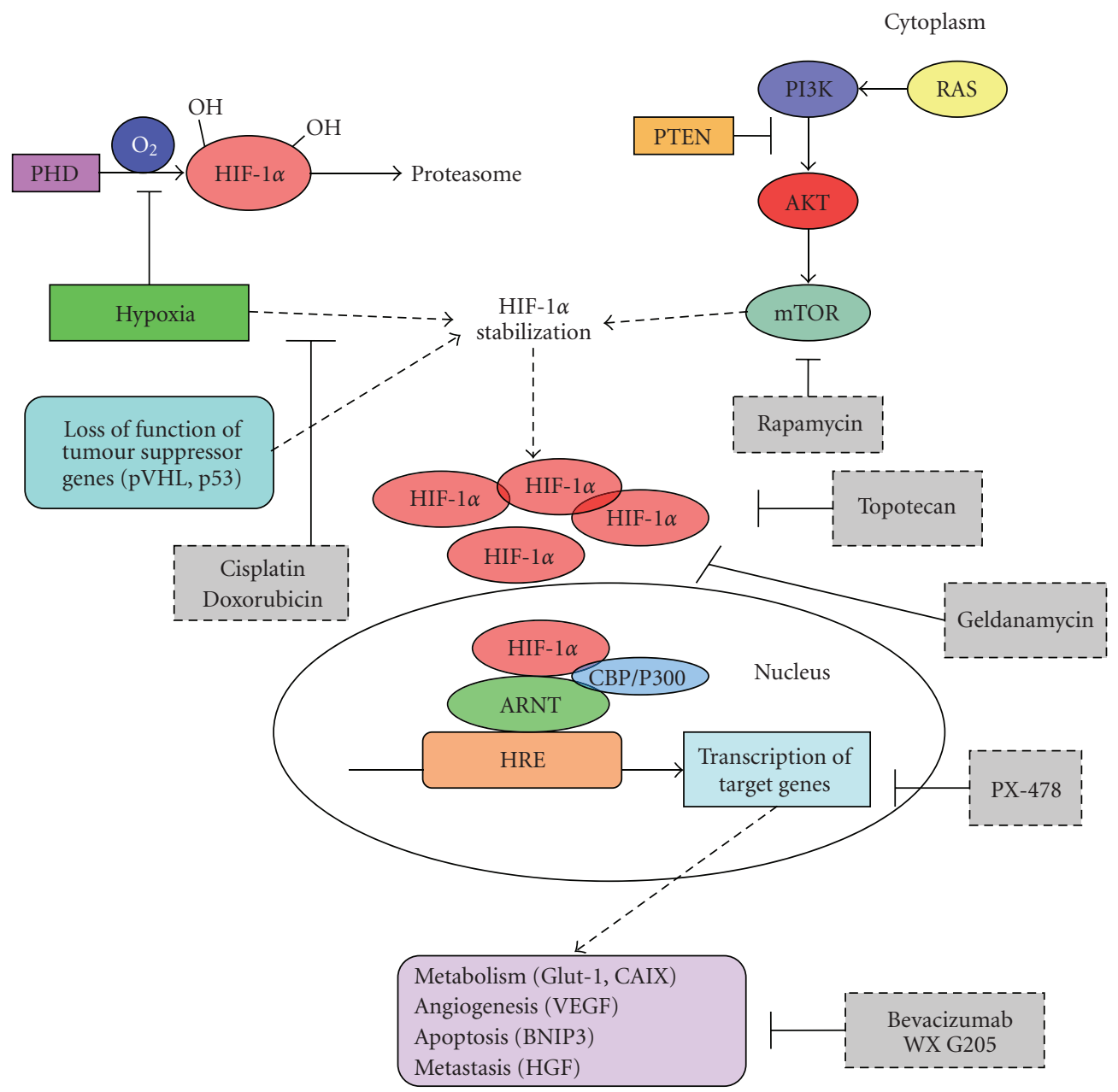

Figure 1: Mechanisms of HIF activation in cancer.

chemotherapy in solid tumours [5-8], targeting HIF-1 could be an attractive treatment strategy, with the potential for disrupting multiple pathways crucial for tumour growth. In this review, we will describe the current status of HIF-1 (upstream and downstream) inhibitors in the treatment of endometrial cancer.

\section{Hypoxia-Inducible Factor-1 $\alpha$}

HIF-1 is a transcription factor composed of the subunits HIF- $1 \alpha$ and HIF- $1 \beta$, which are basic helix-loop-helix DNA binding proteins. Both HIF- $1 \alpha$ and HIF- $1 \beta$ genes are ubiquitously expressed and heterodimerize to form the active HIF-1 that activates gene transcription by binding to the consensus HIF Responsive Element (HRE): 5'-RCGTG$3^{\prime}$ in promoters and enhancers of target genes [9]. The activity of HIF-1 is predominantly regulated at the posttranslational level by regulating HIF- $1 \alpha$ protein stability. At normal oxygen tension, HIF- $1 \alpha$ is hydroxylated by prolyl hydroxylases (PHD) in the oxygen dependent degradation domain (ODDD). Hydroxylated HIF- $1 \alpha$ is recognized by the Von Hippel-Lindau (VHL) protein, ubiquitinated and destined for degradation by proteasomes. This process is inhibited during hypoxia [10]. Under hypoxia, stabilized HIF- $1 \alpha$ subunits heterodimerize with $\beta$ subunits (also known as ARNT) to transactivate target genes after nuclear translocation. Among these are genes involved in adaptation to low glucose levels like the glucose transporter Glut1, carboanhydrase IX (CAIX) that regulates $\mathrm{pH}[11]$, and vascular endothelial growth factor (VEGF) that is one of the most potent inducers of angiogenesis [12]. Although HIF- $1 \alpha$ usually induces prosurvival (CAIX, Glut-1, VEGF) genes, a role of HIF- $1 \alpha$ in regulation of apoptosis has also been described. HIF- $1 \alpha$ promotes cell death through an increase in p53 or other proapoptotic proteins like BNIP3 [13]. As a result of this dual function of HIF-1 $\alpha$, a "stopand-go" strategy as a dynamic balance to maintain overall cell growth and survival has been proposed [14]. Hypoxia induced HIF- $1 \alpha$ also affects the expression of genes involved in metastasis formation. Hepatocyte growth factor (HGF), for example, is a cytokine which stimulates proliferation and invasion through its receptor, the protooncogene c-MET [15]. Invasive cell growth is promoted by HIF- $1 \alpha$-induced cMet transcription and sensitizing of cells to HGF stimulation [16-18]. Taken together, the adaptive response to hypoxia 
in primary tumours resembles in many ways the so-called metastatic phenotype which explains the poor prognosis of hypoxic cancers [19].

HIF-1 stabilization may also occur under oxygenindependent conditions, including infection with oncogenic viruses, loss-of-function mutations in tumour suppressor genes such as Von Hippel-Lindau (VHL), or signaling by receptor tyrosine kinases, prostaglandin E2 receptor, or nitric oxide [20]. Furthermore, genetic alterations in the EGFR [21], RAS, and PI-3K/Akt [22-24] as well as loss of p53 function [25] have been shown to lead to increased nonhypoxic HIF activity. HIF- $1 \alpha$ has also been shown to be regulated by mammalian target of Rapamycin (mTOR). mTOR promotes increased translation of HIF- $1 \alpha$ mRNA into protein $[26,27]$. Other possible mechanisms contributing to normoxic HIF-1 expression like oncogenic mutation or amplification of HIF-1 $\alpha$ gene have rarely been reported in solid cancers $[28,29]$. A polymorphism in HIF- $1 \alpha$ (P582S) has been found associated with increased HIF activity and poor prognosis in prostate cancer, but its significance with cancer risk is still incompletely understood $[30,31]$. The single nucleotide polymorphism (SNP) $\mathrm{C} 1772 \mathrm{~T}$ (also described as C1744T) in the HIF- $1 \alpha$ gene coding region results in an amino acid change at position 582 changing a Proline to a Serine (i.e., P582>S) in the ODD domain (http://www.ncbi.nlm.nih.gov/SNP/snp_ref. cgi?rs=11549465). Carriers of this SNP seemed to have an increased risk of developing cervical and endometrial cancer [32]. However, the proportion of allele carriers with the most common polymorphism in the control group was different from ratios described in other studies. We [31] examined whether the C1744T polymorphism increased the risk for endometrioid endometrial cancer. Although the C1744T polymorphism was associated with higher microvessel density and AKT activation, it did not lead to increased cancer risk. Interestingly we found that the P582S genotype variation in the ODDD of the HIF- $1 \alpha$ protein may occur as a de novo mutation in endometrial cancer. Although the significance of this remains to be established, others have proposed that it may increase transactivation of HIF- $1 \alpha$ [30].

\section{Endometrial Cancer}

3.1. HIF-1 $\alpha$ and Endometrial Carcinogenesis. It has been postulated that menstruation results from vasoconstriction of spiral arterioles, causing hypoxia which leads to necrosis [33]. This focal hypoxia in perimenstrual endometrium could result in locally increased HIF- $1 \alpha$. However, in premenopausal women, HIF- $1 \alpha$ was undetectable in the majority of samples. In the HIF- $1 \alpha$ positive cases, expression was only seen in a small focus within the tissue, suggesting that if hypoxia does occur at this time, then it is not widespread. There seemed to be no correlation of HIF- $1 \alpha$ expression and the menstrual cycle [34]. In postmenopausal women, HIF-1 $\alpha$ was increasingly overexpressed from inactive endometrium through hyperplasia to endometrioid carcinoma, paralleled by activation of its downstream genes such as CAIX, Glut-1, VEGF, and increased angiogenesis. Low HIF- $1 \alpha$ expression was associated with negative/low VEGF staining in the total group [35]. These results highlight the potential importance of hypoxia and its key regulator HIF- $1 \alpha$ in endometrial carcinogenesis and progression of disease [36].

Perinecrotic, chronic hypoxia-associated HIF- $1 \alpha$ expression was absent in inactive endometrium, rare in endometrial hyperplasia, and frequent in endometrioid carcinoma. These results could point to the importance of hypoxia and the subsequent stabilization of HIF- $1 \alpha$ in endometrial carcinogenesis [35-38]. Loss of PTEN tumour suppressor gene (also known as MMAC1) is often seen in endometrial carcinogenesis and is thought to cause nonhypoxia-mediated HIF- $1 \alpha$ expression via activation of the PI3K/AKT and mTOR signaling pathway [39-42]. Horrée et al. (unpublished data) showed that although over $60 \%$ of the carcinomas showed extensive loss of PTEN by immunohistochemistry, this was not correlated to increased HIF- $1 \alpha$ expression. Thus, diffuse nonhypoxia-related expression of HIF- $1 \alpha$ seemed not to be related to PTEN mutation in endometrial cancer. Correlation of HIF- $1 \alpha$ with tumour stage, tumour grade, or myometrial invasion is still under discussion $[35,43,44]$.

The mechanism of tumourigenesis of USPC differs from that of EEC. More expression of HIF- $1 \alpha$ was observed in USPC than in EEC $[44,45]$. In USPC, HIF- $1 \alpha$ expression was not correlated to clinical stage or depth of myometrial invasion. p53 mutations are a common event in USPC carcinogenesis and aberrant p53 accumulation has been associated with HIF- $1 \alpha$ overexpression in different human tumours [46]. In contrast, p53 expression was not associated with HIF- $1 \alpha$ expression in type II endometrial carcinomas $[44,45]$.

3.2. HIF-1 $\alpha$ and Prognosis in Endometrial Cancer. Contradictory results have been described as to the prognostic value of HIF- $1 \alpha$ overexpression in endometrial carcinoma. HIF- $1 \alpha$ showed significantly higher expression in recurrent endometrial carcinomas when compared with their primary tumours; it was, however, not an independent predictor for recurrent endometrial carcinoma [43, 44]. In stage 1 endometrial cancers, HIF- $1 \alpha$ was associated with a worse prognosis [37]. However, others did not find prognostic impact of HIF- $1 \alpha$ expression [38]. Besides the limitation of relatively small numbers of patients in these studies, immunohistochemical studies are difficult to compare because of a variation in definition of HIF- $1 \alpha$ positivity. In some studies, both nuclear and cytoplasmic staining was scored. The significance of cytoplasmic HIF$1 \alpha$, however, is still not clear as stable HIF- $1 \alpha$ is thought to rapidly translocate to the nucleus. Expression patterns that can be observed in endometrial tumours are the diffuse, perinecrotic, and mixed (both perinecrotic and diffuse) patterns [35]. Perinecrotic HIF-1 $\alpha$ expression is thought to be hypoxia driven, whereas diffuse HIF- $1 \alpha$ expression may rather be due to nonhypoxic stimuli [47]. Our experience shows that once authors take into account nuclear staining only and HIF- $1 \alpha$ expression pattern, the results can change dramatically. Figure 2 shows an example of nuclear HIF- $1 \alpha$ in a diffuse and perinecrotic expression pattern. 
TABLE 1: Clinical trials on HIF- $1 \alpha$ targeted therapies in endometrial cancer.

\begin{tabular}{|c|c|c|c|}
\hline Class & Inhibitor & Mechanism & $\begin{array}{l}\text { Clinical trials in } \\
\text { endometrial } \\
\text { cancer }\end{array}$ \\
\hline \multicolumn{4}{|c|}{ Small molecule inhibitors of HIF-1 } \\
\hline Topoisomerase inhibitor & Topotecan (topo-I) & $\begin{array}{l}\text { Inhibits hypoxic } \\
\text { induction of HIF- } 1 \alpha \\
\text { protein and DNA } \\
\text { binding activity }\end{array}$ & $\begin{array}{l}\text { Miller et al. [48] } \\
\text { Triana et al. [49] } \\
\text { Wadler et al. } \\
{[50]}\end{array}$ \\
\hline HSP90 inhibitor & Geldanamycin & $\begin{array}{l}\text { Induces degradation of } \\
\text { HIF- } 1 \alpha \text { protein and } \\
\text { inhibition of DNA } \\
\text { binding of HIF-1 }\end{array}$ & - \\
\hline Other & PX-478 & $\begin{array}{l}\text { Inhibition of HIF- } 1 \alpha \\
\text { transcription activity }\end{array}$ & - \\
\hline \multicolumn{4}{|c|}{ Inhibitors of signal transduction pathways } \\
\hline \multirow[t]{2}{*}{ mTOR inhibitor } & Temsirolimus (CCI-779) & $\begin{array}{l}\text { Downregulation of } \\
\text { HIF- } 1 \alpha \text { by inhibing } \\
\text { mTor }\end{array}$ & Oza et al. [51] \\
\hline & Everolimus (RAD001) & & $\begin{array}{l}\text { Slomovitz et al. } \\
\text { [52] }\end{array}$ \\
\hline \multicolumn{4}{|c|}{ Inhibitors of HIF-1 target genes } \\
\hline VEGF inhibitor & Bevacizumab & $\begin{array}{l}\text { Monoclonal antibody } \\
\text { against VEGF }\end{array}$ & $\begin{array}{l}\text { Aghajanian et al. } \\
\text { [53] }\end{array}$ \\
\hline CAIX inhibitor & Rencarex (WX G250) & $\begin{array}{l}\text { Monoclonal antibody } \\
\text { against CAIX }\end{array}$ & - \\
\hline
\end{tabular}

As HIF- $1 \alpha$ expression is associated with treatment failure and/or patient mortality, targeting HIF- $1 \alpha$ could be an attractive treatment strategy, with the potential for disrupting multiple pathways crucial for tumour growth.

\section{HIF-1 $\alpha$ and Hypoxia as a Target for Cancer Therapy}

The unsatisfactory results obtained with conventional pharmacological treatment encourage further biological and clinical investigations addressed to a better understanding of specific cell targets and signaling transduction pathways involved in endometrial carcinogenesis and to the identification of novel molecular targeted therapies. A new and more effective treatment for metastatic endometrial carcinoma is urgently needed.

There are different areas of research in hypoxia-related drug therapy including (1) designing drugs that directly inhibit HIF-1 signaling and (2) influencing other signaling cascades that indirectly alter HIF signaling.

Inhibition of HIF- $1 \alpha$ would, of course, hit multiple targets but because of its bifunctional effects, for example, proapoptotic genes induced by hypoxia, outcome will be difficult to predict. Thus far, selective HIF-1 inhibitors have not been identified. A number of nonselective inhibitors, which indirectly target signaling pathways upstream or downstream HIF-1 are known to decrease HIF-1 $\alpha$ protein levels. Antisense therapy against HIF-1 $\alpha$ has been shown to reduce HIF- $1 \alpha$ expression and transcriptional activity; however, at present it is not clinically applicable. Therefore, the potential of HIF- $1 \alpha$ as a target for cancer therapy lies in the small molecule inhibitors of HIF-1. Several small molecular inhibitors of the HIF-1 transcriptional activation pathway have been identified (Table 1). Although none of these has been shown to directly and specifically target HIF$1[54,55]$, they do decrease HIF- $1 \alpha$ protein levels. Some of these HIF-1 inhibitors are subject of clinical trials at present.

4.1. Topotecan. Topotecan, a topoisomerase I inhibitor that has been used as a second-line therapy for ovarian cancer, is one such small molecule inhibitor of HIF-1 [56, 57]. Topotecan inhibits hypoxic induction of HIF- $1 \alpha$ protein and DNA binding activity [58]. In a GOG phase II trial of Topotecan in pretreated patients with advanced, persistent, or recurrent endometrial carcinoma, the total response rate was $9 \%$, with 1 patient achieving a complete response and 1 experiencing a partial response. Twelve (55\%) patients maintained stable disease [48]. The eastern Cooperative Oncology Group subsequently performed a phase II trial of Topotecan for metastatic or recurrent endometrial carcinoma. The overall response was $20 \%$. Although singleagent Topotecan treatment has shown activity in chemonaïve [50] and previously treated patients $[48,49]$, severe (grade 4 neutropenia) and unexpected (primarily sepsis) toxicities were encountered $[48,50]$. However, at modified doses, 


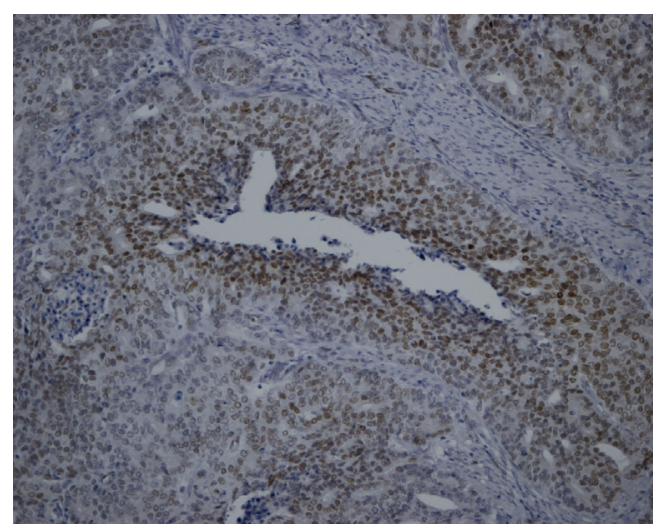

(a)

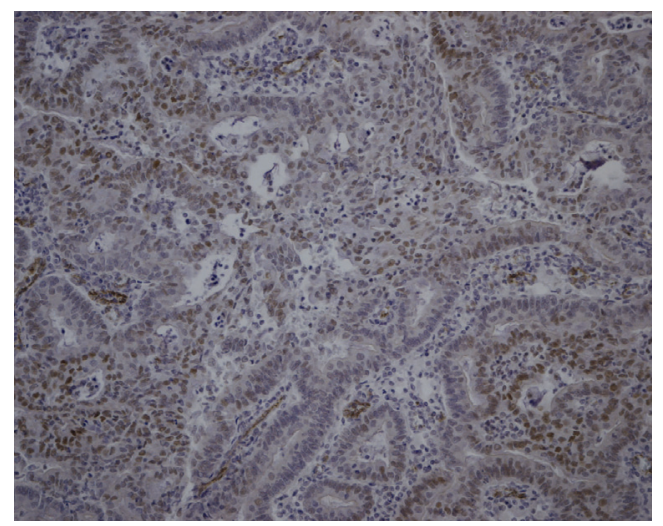

(b)

FIGURE 2: Immunohistochemical staining of HIF-1 $\alpha$ in endometrioid endometrial carcinoma. Typical patterns are shown: (a) perinecrotic HIF- $1 \alpha$ expression $(10 \times$ magnification) and (b) diffuse HIF- $1 \alpha$ expression ( $10 \times$ magnification).

toxicity was acceptable and clinical activity was preserved [50].

Despite the different carcinogenesis of EEC and USPC, but probably due to the rareness of the latter, clinical trials including only USPC patients are rare. A pilot study of Topotecan for the treatment of USPC demonstrated clinical activity in this patient group [59]. However, because survival outcomes continue to be disappointing, combining Topotecan with other active drugs may lead to improved outcomes.

4.2. mTOR Inhibitors. HIF- $1 \alpha$ has also been shown to be regulated by mammalian target of Rapamycin (mTOR). mTOR promotes increased translation of HIF- $1 \alpha$ mRNA into protein $[26,27]$. Rapamycin is a specific inhibitor of mTOR and inhibits both the stabilization and the transcriptional activity of HIF- $1 \alpha$ in hypoxic cancer cells [60]. This effect is directly related to the disruption of mTORdependent signaling functions. The current hypothesis is that mTOR inhibitors could be effective inhibitors of hypoxic adaptation in developing tumours. These effects could be especially relevant in tumours with loss of PTEN function as is often the case in endometrioid endometrial cancer
[61]. Loss of PTEN leads to constitutive activation of AKT, which leads to up-regulation of mTOR. Potential therapies targeting the mTOR pathway include mTOR inhibitors (Rapamycin derivates) Temsirolimus (CCI-779), and Everolimus (RAD001) [62]. Demonstrated activity in preclinical studies has led to numerous phase I and phase II trials. A phase II trial of Temsirolimus in patients with chemotherapy treated, recurrent, or metastatic endometrial cancer showed modest activity of Temsirolimus. Two patients (7.4\%) showed partial response and twelve patients (44\%) had stable disease [51]. A 44\% clinical benefit response rate was found in a phase II study of Everolimus in 29 patients with recurrent endometrial cancer [52]. Clinical Benefit was defined as complete or partial response or prolonged stable disease. In this trial, loss of PTEN expression was predicative of response rate. The different mTOR inhibitors show encouraging single agent clinical benefit. A phase I trial of Temsirolimus with Topotecan (NCT00523432) in patients with gynaecological malignancies, including endometrial cancer, has just finished recruiting patients. Other trials of Temsirolimus are underway.

4.3. Bevacizumab. An HIF-1 inhibitor that targets a pathway activated by HIF-1 is Bevacizumab. Bevacizumab is a monoclonal antibody that targets VEGF, a potent endothelial cell mitogen that has been associated with increased angiogenesis in malignancies. Different studies showed that an increase in VEGF expression was linked to increased angiogenesis in endometrial carcinomas. High VEGF mRNA levels were correlated significantly with highly vascularized tumours $[63,64]$. Early results of a phase II study of Bevacizumab in the treatment of recurrent or persistent endometrial cancer in 53 patients showed a $15 \%$ response rate. Nearly 36\% of the patients were progression free at 6 months [53]. In conclusion, Bevacizumab appears to be active in women with recurrent or persistent endometrial cancer.

4.4. Cisplatin and Doxorubicin. Some conventional anticancer agents targeting signal transduction pathways have also been shown to inhibit HIF-1 [65]. Duyndam et al. [66] showed in human ovarian cancer cell lines that the conventional anticancer agents cisplatin and doxorubicin can negatively influence HIF-1 activity with a concomitant reduction of VEGF expression. A recent phase III trial demonstrated improved progression-free and overall survival for the three-drug regimen of cisplatin, doxorubicin and paclitaxel compared with a two-drug combination (cisplatin and doxorubicin) in advanced or recurrent endometrial carcinoma. However, toxicity problems often make the three-drug regimen less acceptable [67].

4.5. New Promising Drugs. Small molecule inhibitors of HIF-1 activity currently investigated in clinical trials are PX-478, an inhibitor of HIF-1 transcription factor activity [68], and geldanamycin, an HSP90 (heat shock protein 90) inhibitor [69]. HSP90 is involved in the folding of HIF- $1 \alpha$ and Geldanamycin induces degradation of HIF-1 $\alpha$ [70]. Both are being evaluated in advanced solid tumours. WX G250, 
a CAIX antibody (http://www.wilex.com), is another HIF-1 inhibitor that targets a different pathway activated by HIF1. WX G250 is currently in phase III clinical trials in renal cell cancers. These new drugs may find their way into clinical trials in endometrial cancer in the future.

\section{Summary}

Hypoxic tumours are usually resistant to radiotherapy and conventional chemotherapy, rendering them highly aggressive and metastatic. Response to hypoxic stress is largely mediated by the HIF pathway. HIF- $1 \alpha$ expression is correlated with a poor prognosis in endometrial cancer. Therefore, targeting the HIF pathway provides an attractive strategy to treat hypoxic and highly angiogenic tumours. Thus far, selective HIF-1 inhibitors have not been identified. A number of nonselective inhibitors, which indirectly target signaling pathways upstream or downstream of HIF-1, are known to decrease the key regulating HIF- $1 \alpha$ protein levels. Different (indirect) HIF- $1 \alpha$ inhibitors that are in clinical trial for the treatment of advanced/recurrent endometrial carcinoma are Topotecan, Rapamycin derivates, and Bevacizumab. Preliminary results show encouraging results for these singleagent treatments with partial response and stable disease in the patients. However, lack of specificity increases the difficulty in attributing any antitumorigenic effects of these drugs specifically to inhibition of HIF-1. The combination of HIF inhibitors with conventional treatment may prove to be clinically useful. Further work is needed to identify more selective HIF-1 inhibitors, to determine their mechanism of action, and to translate these developments into clinical trials.

\section{References}

[1] A. Jemal, R. Siegel, E. Ward, Y. Hao, J. Xu, and M. J. Thun, "Cancer statistics, 2009," CA: A Cancer Journal for Clinicians, vol. 59, pp. 225-249, 2009.

[2] I. J. Fidler and L. M. Ellis, "The implications of angiogenesis for the biology and therapy of cancer metastasis," Cell, vol. 79, no. 2, pp. 185-188, 1994.

[3] T. Kurokawa, M. Miyamoto, K. Kato, et al., "Overexpression of hypoxia-inducible-factor $1 \alpha(\mathrm{HIF}-1 \alpha)$ in oesophageal squamous cell carcinoma correlates with lymph node metastasis and pathologic stage," British Journal of Cancer, vol. 89, no. 6, pp. 1042-1047, 2003.

[4] Q. T. Le, N. C. Denko, and A. J. Giaccia, "Hypoxic gene expression and metastasis," Cancer and Metastasis Reviews, vol. 23, no. 3-4, pp. 293-310, 2004.

[5] M. Höckel, K. Schlenger, S. Höckel, and P. Vaupel, "Hypoxic cervical cancers with low apoptotic index are highly aggressive," Cancer Research, vol. 59, no. 18, pp. 4525-4528, 1999.

[6] P. Vaupel, O. Thews, and M. Hoeckel, "Treatment resistance of solid tumors: role of hypoxia and anemia," Medical Oncology, vol. 18, no. 4, pp. 243-259, 2001.

[7] A. E. Greijer, M. C. de Jong, G. L. Scheffer, A. Shvarts, P. J. van Diest, and E. van der Wall, "Hypoxia-induced acidification causes mitoxantrone resistance not mediated by drug transporters in human breast cancer cells," Cellular Oncology, vol. 27, no. 1, pp. 43-49, 2005.
[8] L. Harrison and K. Blackwell, "Hypoxia and anemia: factors in decreased sensitivity to radiation therapy and chemotherapy?" Oncologist, vol. 9, supplement 5, pp. 31-40, 2004.

[9] G. L. Semenza, "Regulation of mammalian $\mathrm{O}_{2}$ homeostasis by hypoxia-inducible factor 1," Annual Review of Cell and Developmental Biology, vol. 15, pp. 551-578, 1999.

[10] L. E. Huang, Z. Arany, D. M. Livingston, and H. F. Bunn, "Activation of hypoxia-inducible transcription factor depends primarily upon redox-sensitive stabilization of its $\alpha$ subunit," The Journal of Biological Chemistry, vol. 271, no. 50, pp. 32253-32259, 1996.

[11] R. D. Vaughan-Jones and K. W. Spitzer, "Role of bicarbonate in the regulation of intracellular $\mathrm{pH}$ in the mammalian ventricular myocyte," Biochemistry and Cell Biology, vol. 80, no. 5, pp. 579-596, 2002.

[12] K. S. Choi, M. K. Bae, J. W. Jeong, H. E. Moon, and K. W. Kim, "Hypoxia-induced angiogenesis during carcinogenesis," Journal of Biochemistry and Molecular Biology, vol. 36, no. 1, pp. 120-127, 2003.

[13] T. Schmid, J. Zhou, and B. Brüne, "HIF-1 and p53: communication of transcription factors under hypoxia," Journal of Cellular and Molecular Medicine, vol. 8, no. 4, pp. 423-431, 2004.

[14] M. Koshiji and L. E. Huang, "Dynamic balancing of the dual nature of HIF- $1 \alpha$ for cell survival," Cell Cycle, vol. 3, no. 7, pp. 853-854, 2004.

[15] K. A. Furge, Y. W. Zhang, and G. F. Vande Woude, "Met receptor tyrosine kinase: enhanced signaling through adapter proteins," Oncogene, vol. 19, no. 49, pp. 5582-5589, 2000.

[16] S. Pennacchietti, P. Michieli, M. Galluzzo, M. Mazzone, S. Giordano, and P. M. Comoglio, "Hypoxia promotes invasive growth by transcriptional activation of the met protooncogene," Cancer Cell, vol. 3, no. 4, pp. 347-361, 2003.

[17] S. Hara, K. Nakashiro, S. K. Klosek, T. Ishikawa, S. Shintani, and H. Hamakawa, "Hypoxia enhances c-Met/HGF receptor expression and signaling by activating HIF- $1 \alpha$ in human salivary gland cancer cells," Oral Oncology, vol. 42, no. 6, pp. 593-598, 2006.

[18] C. Eckerich, S. Zapf, R. Fillbrandt, S. Loges, M. Westphal, and K. Lamszus, "Hypoxia can induce c-Met expression in glioma cells and enhance SF/HGF-induced cell migration," International Journal of Cancer, vol. 121, no. 2, pp. 276-283, 2007.

[19] E. H. Gort, A. J. Groot, E. van der Wall, P. J. van Diest, and M. A. Vooijs, "Hypoxic regulation of metastasis via hypoxiainducible factors," Current Molecular Medicine, vol. 8, no. 1, pp. 60-67, 2008.

[20] W. G. Kaelin Jr., "The von Hippel-Lindau tumor suppressor protein and clear cell renal carcinoma," Clinical Cancer Research, vol. 13, no. 2, part 2, pp. 680s-682s, 2007.

[21] E. Laughner, P. Taghavi, K. Chiles, P. C. Mahon, and G. L. Semenza, "HER2 (neu) signaling increases the rate of hypoxiainducible factor $1 \alpha$ (HIF-1 $\alpha$ ) synthesis: novel mechanism for HIF-1-mediated vascular endothelial growth factor expression," Molecular and Cellular Biology, vol. 21, no. 12, pp. 39954004, 2001.

[22] W. Zundel, C. Schindler, D. Haas-Kogan, et al., "Loss of PTEN facilitates HIF-1-mediated gene expression," Genes and Development, vol. 14, no. 4, pp. 391-396, 2000.

[23] E. H. Gort, A. J. Groot, T. L. P. Derks van de Ven, et al., "Hypoxia-inducible factor- $1 \alpha$ expression requires PI 3-kinase activity and correlates with Aktl phosphorylation in invasive breast carcinomas," Oncogene, vol. 25, no. 45, pp. 6123-6127, 2006. 
[24] B. H. Jiang, G. Jiang, J. Z. Zheng, Z. Lu, T. Hunter, and P. K. Vogt, "Phosphatidylinositol 3-kinase signaling controls levels of hypoxia-inducible factor 1," Cell Growth and Differentiation, vol. 12, no. 7, pp. 363-369, 2001.

[25] R. Ravi, B. Mookerjee, Z. M. Bhujwalla, et al., "Regulation of tumor angiogenesis by $\mathrm{p} 53$-induced degradation of hypoxiainducible factor $1 \alpha$," Genes and Development, vol. 14, no. 1, pp. 34-44, 2000.

[26] C. Treins, S. Giorgetti-Peraldi, J. Murdaca, G. L. Semenza, and E. Van Obberghen, "Insulin stimulates hypoxia-inducible factor 1 through a phosphatidylinositol 3-kinase/target of rapamycin-dependent signaling pathway," The Journal of Biological Chemistry, vol. 277, no. 31, pp. 27975-27981, 2002.

[27] C. C. Hudson, M. Liu, G. G. Chiang, et al., "Regulation of hypoxia-inducible factor $1 \alpha$ expression and function by the mammalian target of rapamycin," Molecular and Cellular Biology, vol. 22, no. 20, pp. 7004-7014, 2002.

[28] M. M. Vleugel, A. E. Greijer, E. van der Wall, and P. J. van Diest, "Mutation analysis of the HIF- $1 \alpha$ oxygen-dependent degradation domain in invasive breast cancer," Cancer Genetics and Cytogenetics, vol. 163, no. 2, pp. 168-172, 2005.

[29] M. M. Vleugel, R. Bos, H. Buerger, et al., "No amplifications of hypoxia-inducible factor- $1 \alpha$ gene in invasive breast cancer: a tissue microarray study," Cellular Oncology, vol. 26, no. 5-6, pp. 347-351, 2004.

[30] X. S. Fu, E. Choi, G. J. Bubley, and S. P. Balk, "Identification of hypoxia-inducible factor- $1 \alpha$ (HIF- $1 \alpha)$ polymorphism as a mutation in prostate cancer that prevents normoxia-induced degradation," Prostate, vol. 63, no. 3, pp. 215-221, 2005.

[31] N. Horree, A. J. Groot, W. van Hattem, A. P. Heintz, M. A. Vooijs, and P. J. van Diest, "HIF-1 $\alpha$ gene mutations are associated with higher microvessel density in endometrial carcinomas," Histopathology, vol. 52, no. 5, pp. 637-639, 2008.

[32] E. Konac, H. I. Onen, J. Metindir, E. Alp, A. A. Biri, and A. Ekmekci, "An investigation of relationships between hypoxiainducible factor- $1 \alpha$ gene polymorphisms and ovarian, cervical and endometrial cancers," Cancer Detection and Prevention, vol. 31, no. 2, pp. 102-109, 2007.

[33] L. Speroff, R. H. Glass, and N. G. Kase, Clinical Gynecologic Endocrinology and Infertility, Williams and Wilkins, Sydney, Australia, 1994.

[34] J. Zhang and L. A. Salamonsen, "Expression of hypoxiainducible factors in human endometrium and suppression of matrix metalloproteinases under hypoxic conditions do not support a major role for hypoxia in regulating tissue breakdown at menstruation," Human Reproduction, vol. 17, no. 2, pp. 265-274, 2002.

[35] N. Horrée, P. J. van Diest, P. van der Groep, D. M. Sie-Go, and A. P. Heintz, "Hypoxia and angiogenesis in endometrioid endometrial carcinogenesis," Cellular Oncology, vol. 29, no. 3, pp. 219-227, 2007.

[36] I. H. Ozbudak, S. Karaveli, T. Simsek, G. Erdogan, and E. Pestereli, "Neoangiogenesis and expression of hypoxiainducible factor $1 \alpha$, vascular endothelial growth factor, and glucose transporter-1 in endometrioid type endometrium adenocarcinomas," Gynecologic Oncology, vol. 108, pp. 603608, 2008.

[37] E. Sivridis, A. Giatromanolaki, K. C. Gatter, A. L. Harris, and M. I. Koukourakis, "Association of hypoxia-inducible factors $1 \alpha$ and $2 \alpha$ with activated angiogenic pathways and prognosis in patients with endometrial carcinoma," Cancer, vol. 95, no. 5, pp. 1055-1063, 2002.
[38] G. Acs, X. Xu, C. Chu, P. Acs, and A. Verma, "Prognostic significance of erythropoietin expression in human endometrial carcinoma," Cancer, vol. 100, no. 11, pp. 2376-2386, 2004.

[39] J. I. Risinger, A. K. Hayes, A. Berchuck, and J. C. Barrett, "PTEN/MMAC1 mutations in endometrial cancers," Cancer Research, vol. 57, no. 21, pp. 4736-4738, 1997.

[40] D. Kong, A. Suzuki, T. T. Zou, et al., "PTEN1 is frequently mutated in primary endometrial carcinomas," Nature Genetics, vol. 17, no. 2, pp. 143-144, 1997.

[41] D. E. Cohn, J. B. Basil, A. R. Venegoni, et al., "Absence of PTEN repeat tract mutation in endometrial cancers with microsatellite instability," Gynecologic Oncology, vol. 79, no. 1, pp. 101-106, 2000.

[42] M. Cully, H. You, A. J. Levine, and T. W. Mak, "Beyond PTEN mutations: the PI3K pathway as an integrator of multiple inputs during tumorigenesis," Nature Reviews Cancer, vol. 6, no. 3, pp. 184-192, 2006.

[43] J. M. A. Pijnenborg, M. Wijnakker, J. Hagelstein, B. Delvoux, and P. G. Groothuis, "Hypoxia contributes to development of recurrent endometrial carcinoma," International Journal of Gynecological Cancer, vol. 17, no. 4, pp. 897-904, 2007.

[44] V. Pansare, A. R. Munkarah, V. Schimp, et al., "Increased expression of hypoxia-inducible factor $1 \alpha$ in type I and type II endometrial carcinomas," Modern Pathology, vol. 20, no. 1, pp. 35-43, 2007.

[45] V. L. Schimp, R. Ali-Fehmi, L. A. Solomon, et al., "The racial disparity in outcomes in endometrial cancer: could this be explained on a molecular level?” Gynecologic Oncology, vol. 102, no. 3, pp. 440-446, 2006.

[46] H. Zhong, A. M. De Marzo, E. Laughner, et al., "Overexpression of hypoxia-inducible factor $1 \alpha$ in common human cancers and their metastases," Cancer Research, vol. 59, no. 22, pp. 5830-5835, 1999.

[47] M. M. Vleugel, A. E. Greijer, A. Shvarts, et al., "Differential prognostic impact of hypoxia induced and diffuse HIF$1 \alpha$ expression in invasive breast cancer," Journal of Clinical Pathology, vol. 58, no. 2, pp. 172-177, 2005.

[48] D. S. Miller, J. A. Blessing, S. S. Lentz, S. E. Waggoner, and D. Mackey, "A phase II trial of topotecan in patients with advanced, persistent, or recurrent endometrial carcinoma: a gynecologic oncology group study," Gynecologic Oncology, vol. 87, no. 3, pp. 247-251, 2002.

[49] T. A. Traina, P. Sabbatini, C. Aghajanian, and J. Dupont, "Weekly topotecan for recurrent endometrial cancer: a case series and review of the literature," Gynecologic Oncology, vol. 95, no. 1, pp. 235-241, 2004.

[50] S. Wadler, D. E. Levy, S. T. Lincoln, G. S. Soori, J. C. Schink, and G. Goldberg, "Topotecan is an active agent in the first-line treatment of metastatic or recurrent endometrial carcinoma: Eastern Cooperative Oncology Group Study E3E93," Journal of Clinical Oncology, vol. 21, no. 11, pp. 2110-2114, 2003.

[51] A. M. Oza, L. Elit, D. Provencher, et al., "A phase II study of temsirolimus (CCI-779) in patients with metastatic and/or locally advanced recurrent endometrial cancer previously treated with chemotherapy: NCIC CTG IND 160b," Journal of Clinical Oncology, vol. 26, no. 5, supplement, p. 5516, 2003.

[52] B. M. Slomovitz, K. H. Lu, T. Johnston, et al., "A pahse II study of oral mammalian target of rapamycin (mTOR) inhibitor, RAD001 (everolimus), in patients with recurrent endometrial carcinoma (EC)," Journal of Clinical Oncology, vol. 26, no. 20, supplement, p. 5502, 2008. 
[53] C. Aghajanian, M. W. Sill, K. Darcy, et al., "A phase II evaluation of bevacizumab in the treatment of recurrent or persistent endometrial cancer: a Gynecologic Oncology Group (GOG) Study," Journal of Clinical Oncology, vol. 27, no. 15, supplement, p. 5531, 2009.

[54] G. L. Semenza, "Targeting HIF-1 for cancer therapy," Nature Reviews Cancer, vol. 3, no. 10, pp. 721-732, 2003.

[55] A. Giaccia, B. G. Siim, and R. S. Johnson, "HIF-1 as a target for drug development," Nature Reviews Drug Discovery, vol. 2, no. 10, pp. 803-811, 2003.

[56] A. Rapisarda, R. H. Shoemaker, and G. Melillo, "Targeting topoisomerase I to inhibit hypoxia inducible factor 1," Cell Cycle, vol. 3, no. 2, pp. 172-175, 2004.

[57] A. Rapisarda and G. Melillo, "UVC inhibits HIF-1alpha protein translation by a DNA damage- and topoisomerase Iindependent pathway," Oncogene, vol. 26, no. 48, pp. 68756884, 2007.

[58] A. Rapisarda, B. Uranchimeg, D. A. Scudiero, et al., "Identification of small molecule inhibitors of hypoxia-inducible factor 1 transcriptional activation pathway," Cancer Research, vol. 62, no. 15, pp. 4316-4324, 2002.

[59] J. T. Chambers, T. J. Rutherford, P. E. Schwartz, M. L. Carcangiu, S. K. Chambers, and L. Baker, "A pilot study of topotecan in the treatment of serous carcinoma of the uterus," International Journal of Gynecological Cancer, vol. 13, no. 2, pp. 216-222, 2003.

[60] H. Zhong, K. Chiles, D. Feldser, et al., "Modulation of hypoxia-inducible factor $1 \alpha$ expression by the epidermal growth factor/phosphatidylinositol 3-kinase/PTEN/AKT/ FRAP pathway in human prostate cancer cells: implications for tumor angiogenesis and therapeutics," Cancer Research, vol. 60, no. 6, pp. 1541-1545, 2000.

[61] M. S. Neshat, I. K. Mellinghoff, C. Tran, et al., "Enhanced sensitivity of PTEN-deficient tumors to inhibition of FRAP/mTOR," Proceedings of the National Academy of Sciences of the United States of America, vol. 98, no. 18, pp. 10314-10319, 2001.

[62] H. S. Chon, W. Hu, and J. J. Kavanagh, "Targeted therapies in gynecologic cancers," Current Cancer Drug Targets, vol. 6, no. 4, pp. 333-363, 2006.

[63] A. Giatromanolaki, E. Sivridis, R. Brekken, et al., "he angiogenic "vascular endothelial growth factor/flk-1(KDR) receptor" pathway in patients with endometrial carcinoma: prognostic and therapeutic implications," Cancer, vol. 92, pp. 2569-2577, 2001.

[64] N. Seki, J. Kodama, A. Hongo, Y. Miyagi, M. Yoshinouchi, and T. Kudo, "Vascular endothelial growth factor and plateletderived endothelial cell growth factor expression are implicated in the angiogenesis of endometrial cancer," European Journal of Cancer, vol. 36, no. 1, pp. 68-73, 2000.

[65] D. Rischin, L. Peters, R. Hicks, et al., "Phase I trial of concurrent tirapazamine, cisplatin, and radiotherapy in patients with advanced head and neck cancer," Journal of Clinical Oncology, vol. 19, no. 2, pp. 535-542, 2001.

[66] M. C. A. Duyndam, M. P. A. van Berkel, J. C. Dorsman, D. A. P. Rockx, H. M. Pinedo, and E. Boven, "Cisplatin and doxorubicin repress Vascular Endothelial Growth Factor expression and differentially down-regulate Hypoxiainducible Factor I activity in human ovarian cancer cells," Biochemical Pharmacology, vol. 74, no. 2, pp. 191-201, 2007.
[67] G. F. Fleming, V. L. Brunetto, D. Cella, et al., "Phase III trial of doxorubicin plus cisplatin with or without paclitaxel plus filgrastim in advanced endometrial carcinoma: a Gynecologic Oncology Group Study," Journal of Clinical Oncology, vol. 22, no. 11, pp. 2159-2166, 2004.

[68] S. Welsh, R. Williams, L. Kirkpatrick, G. Paine-Murrieta, and G. Powis, "Antitumor activity and pharmacodynamic properties of PX-478, an inhibitor of hypoxia-inducible factor-1 $\alpha$," Molecular Cancer Therapeutics, vol. 3, no. 3, pp. 233-244, 2004.

[69] J. L. O’Donnell, M. R. Joyce, A. M. Shannon, J. Harmey, J. Geraghty, and D. Bouchier-Hayes, "Oncological implications of hypoxia inducible factor- $1 \alpha$ (HIF- $1 \alpha$ ) expression," Cancer Treatment Reviews, vol. 32, no. 6, pp. 407-416, 2006.

[70] E. Minet, D. Mottet, G. Michel, et al., "Hypoxia-induced activation of HIF-1: role of HIF- $1 \alpha$-Hsp 90 interaction," FEBS Letters, vol. 460, no. 2, pp. 251-256, 1999. 


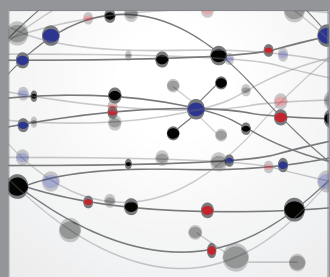

The Scientific World Journal
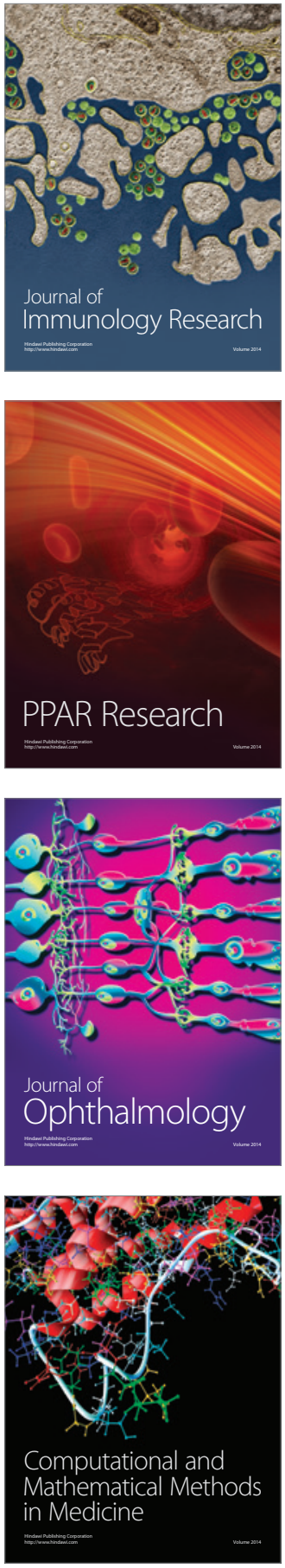

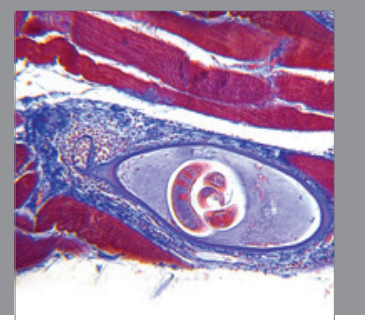

Gastroenterology

Research and Practice
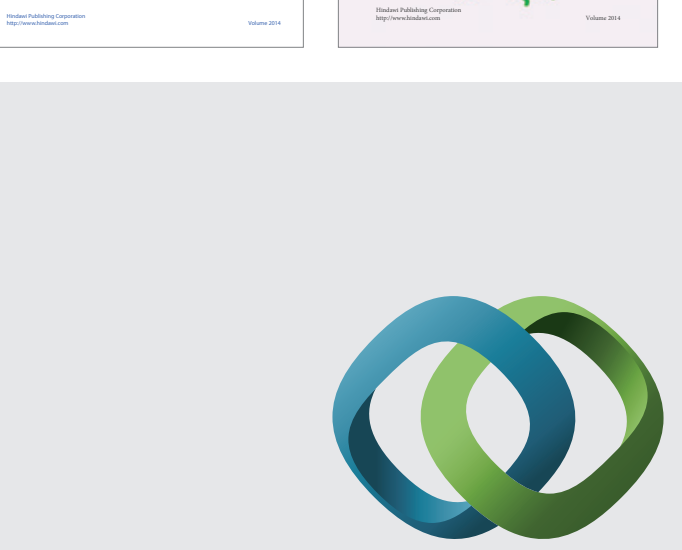

\section{Hindawi}

Submit your manuscripts at

http://www.hindawi.com
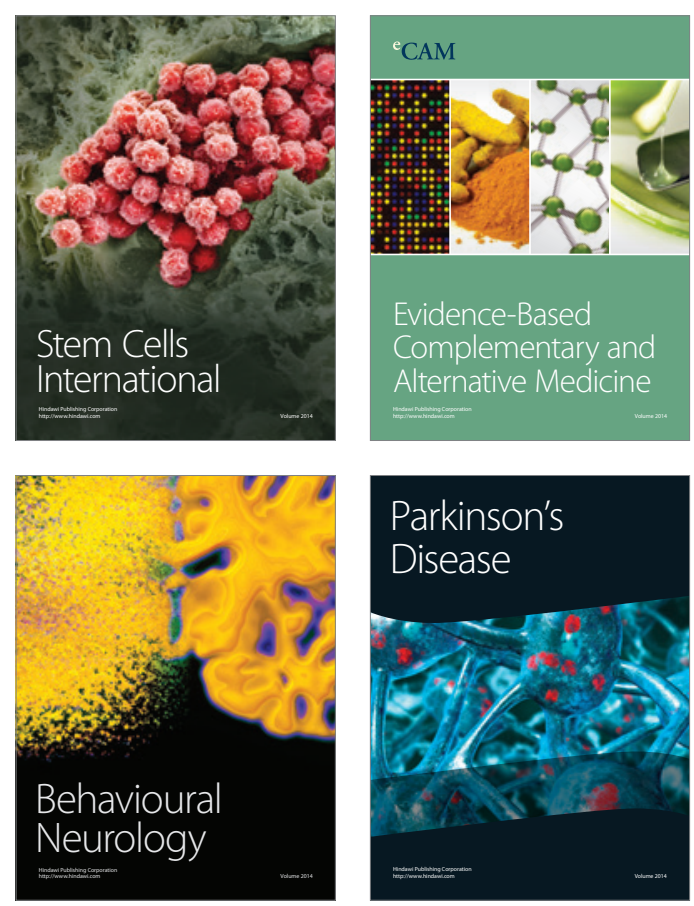

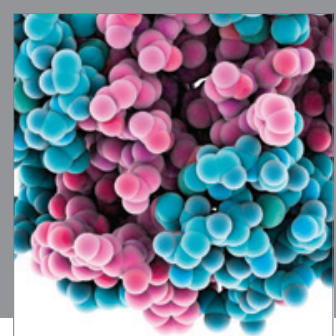

Journal of
Diabetes Research

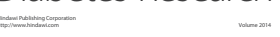

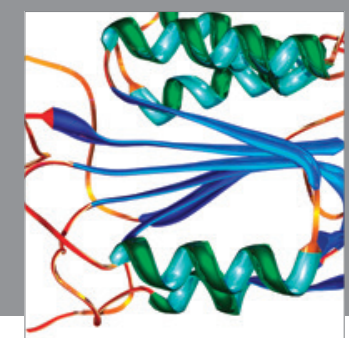

Disease Markers
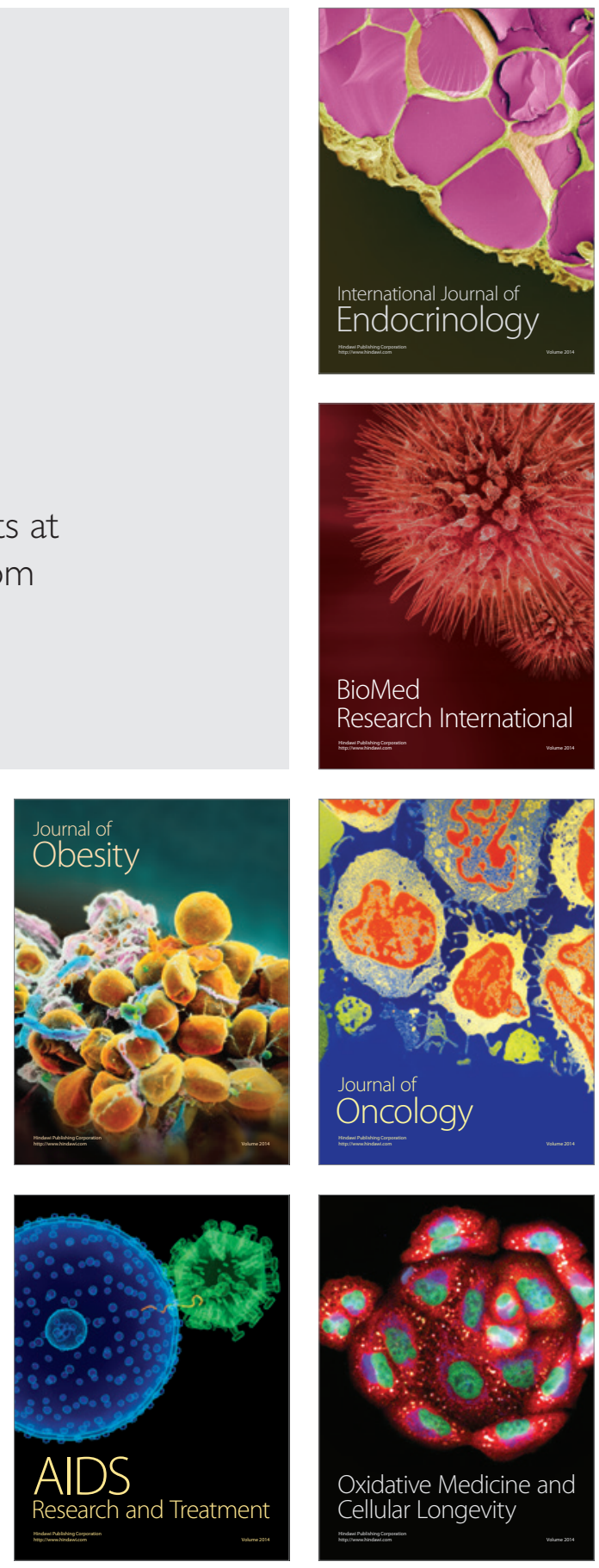